\title{
Investigando processos de comunicação alternativa via tecnologia tangível: um estudo exploratório
}

\author{
Eliana Alves Moreira ${ }^{1,2}$, M. Cecília C. Baranauskas ${ }^{1}$ \\ ${ }^{1}$ Instituto de Computação \& NIED - Universidade Estadual de Campinas (UNICAMP) \\ Av. Albert Einstein, 1251 - 13.083-852 - Campinas - SP - Brasil \\ ${ }^{2}$ Instituto Federal de São Paulo (IFSP) \\ Av. Salgado Filho, 3501 - 07115-000 - Guarulhos - SP - Brasil \\ \{eliana.moreira, cecilia\}@ic.unicamp.br
}

\begin{abstract}
Augmentative and Alternative Communication (AAC) encompasses the materials and methods intended to assist speech-impaired people. We investigated the AAC subject outside the context of disability and proposed a ludic system aimed at promoting communication skills, social interaction and association of ideas via tangible technologies. Preliminary results from Workshops involving children and teachers from a partner institution showed that participants were able to communicate without betaking to speech, by employing resources from the system. Furthermore, participants appeared to be satisfied and motivated by both the tangible interface and team interaction. Results encourage studies of the system in the context of inclusive education.
\end{abstract}

Resumo. Comunicação Alternativa e Aumentativa (CAA) engloba os métodos e materiais propostos para a comunicação de pessoas com deficiência na fala. Investigamos a temática da CAA fora do contexto da deficiência, propondo um sistema lúdico, para promover habilidades de comunicação, interação social e associação de ideias, via tecnologia tangível. Resultados preliminares de Oficinas com crianças e professores de uma instituição parceira evidenciaram que eles conseguiram se comunicar sem a necessidade do uso da fala, utilizando-se de elementos do ambiente proposto, mostrando-se motivados e satisfeitos com o uso da interface tangivel e interação em equipe. Resultados encorajam o estudo do ambiente em contexto da educação inclusiva.

\section{Introdução}

A Convenção Internacional sobre os Direitos das Pessoas com Deficiência (CIDPD), promulgada no Brasil por meio do Decreto $n^{\circ} 6.949$ de 25 de agosto de 2009 [Brasil 2009], referencia o "direito de cada pessoa em escolher ou exercer com autonomia o método de comunicação de sua preferência, assegurando-lhe o desenvolvimento de todas as suas capacidades para uma vida independente". "Comunicação" abrange as línguas, a visualização de textos, o Braille, a comunicação tátil, os caracteres ampliados, os dispositivos de multimídia acessível, assim como a linguagem simples, escrita e oral, os sistemas auditivos e os meios de voz digitalizada e os modos, meios e formatos aumentativos e alternativos de comunicação, inclusive a tecnologia da informação e comunicação acessíveis [Brasil 2009]. Quando há dificuldades em oralizar é necessário 
criar alternativas o mais cedo possível para que o desenvolvimento da pessoa não seja comprometido [Ponte 2009]. Um conjunto de ferramentas e estratégias que o sujeito pode utilizar para resolver os desafios da comunicação é a Comunicação Alternativa e Aumentativa - CAA, que funciona como um complemento e/ou substituição da fala, que pretende compensar a dificuldade de expressão [ASHA 2016]; é a área da tecnologia assistiva que se destina especificamente à ampliação de habilidades de comunicação. Assim, a CAA pode ser empregada para melhorar a comunicação, além de possivelmente promover o desenvolvimento do vocabulário e utilização de mensagens mais complexas. Em essência, no que tange à eliminação de barreiras de comunicação, a própria CIDPD sugere que o Desenho Universal (ou inclusivo) deva ser utilizado para um desenvolvimento inclusivo e sustentável de tecnologia. O desenho inclusivo pode ser definido como a composição de um ambiente que possa ser acessado, compreendido e usado na maior extensão possível, por todas as pessoas, independentemente da sua idade, tamanho, capacidade ou incapacidade [CEUD 2016].

Sistemas de comunicação baseados em imagens são uma forma de tecnologia de CAA que se baseia na utilização de símbolos gráficos para comunicação. Vários pesquisadores, tais como Hayes et al. (2010) e Leo e Leroy (2008), têm proposto ferramentas que se fundamentam nestes sistemas, simulando pranchas de comunicação, utilizando o uso de smartphones e tablets. Dentre as tecnologias digitais contemporâneas que proporcionam ou potencializam a CAA podemos citar também aquelas com interfaces tangíveis. As interfaces tangíveis dão forma física à informação digital, empregando artefatos físicos que, quando manipulados, funcionam como representações físicas da informação digital [Ullmer e Ishii 2000]. Um exemplo de ferramenta que utiliza interação tangível é o "Linguabytes", cujo objetivo é facilitar a criação de um espaço comum de interação e comunicação. O Linguabytes utiliza tecnologia RFID, por meio do uso de um acervo de material lúdico, onde as crianças podem ler histórias interativas e fazer exercícios de natureza linguística [Hengeveld et al. 2013]. Esse trabalho, voltado para crianças de até quatro anos de idade, não tem como objetivo a interação social e propõe uma plataforma própria, por meio de caixas de madeira e módulos de controle, onde são colocados os materiais interativos para a comunicação. A ferramenta "Language Acquisition Manipulatives Blending Earlychildhood Research and Technology" - LAMBERT - é um trabalho voltado para crianças de até três anos de idade e utiliza cartões RFID para "etiquetar" objetos concretos que são associados a palavras, sons, vídeos e fotografias representativas, que são mostradas quando uma criança "escolhe" determinado objeto [Parton et al. 2010].

Este trabalho investiga se e como tecnologias contemporâneas tangíveis podem ser exploradas em benefício da comunicação e interação social de forma criativa, lúdica e acessível para a maior extensão possível de usuários. Nesse sentido, ampliamos o termo para Comunicação Alternativa, Aumentativa e Criativa - CAAC. Além disso, propomos também um sistema que seja de fácil manipulação e instalação, baseado em dispositivos de RFID de fácil acesso. Uma vez que pretendemos um cenário onde todos se comunicam, independentemente da oralidade ou idade, nosso pressuposto para a proposição de uma solução de design de um sistema para a CAAC é o de que se deve considerar o uso do desenho universal. Ilustramos a proposta com o design e desenvolvimento de um ambiente que serviu ao estudo exploratório do tema. Um protótipo na forma de jogo foi experimentado ao longo de cinco oficinas com crianças e 
V Congresso Brasileiro de Informática na Educação (CBIE 2016)

Anais do XXVII Simpósio Brasileiro de Informática na Educação (SBIE 2016)

professores, que realimentaram o processo de design do ambiente. A intenção de trabalhar com tecnologias tangíveis se dá pelo fato de que nos ambientes baseados nestas tecnologias o computador "desaparece" e o usuário pode fazer uso do sistema de forma mais natural, além de que a tecnologia tangível oferece maior facilidade de utilização em relação ao mouse e teclado. Além disso, o uso de materiais tangíveis estimula os múltiplos sentidos e o desenvolvimento de funções cognitivas e habilidades de percepção e corporais [Garzotto et al. 2010].

Este artigo está organizado da seguinte maneira: a seção 2 descreve um cenário exploratório para a CAAC, a seção 3 apresenta o estudo envolvendo esse cenário, a seção 4 apresenta resultados e discussão e, por fim, a seção 5 apresenta a conclusão.

\section{Um cenário exploratório para CAAC}

O jogo e a brincadeira são fenômenos culturais que constituem importantes fatores de desenvolvimento de crianças e de adolescentes porque estimulam o exercício do pensamento e várias habilidades como observação, concentração, perspicácia, cooperação, trabalho em grupo. Com o jogo é possível criar, liberar emoções, dialogar, fazer amigos, interagir com os outros [Kishimoto 1994]. O jogo desenvolve a imaginação direcionando para uma crescente socialização [Deus et al. 2011].

Para criar um cenário exploratório para a CAAC implementamos, em plataforma tangível, um jogo de adivinhações, onde os usuários utilizam cartões para se comunicar, por meio da escolha de figuras representativas, em alusão ao uso das pranchas/cartões de comunicação utilizadas com pessoas com deficiência na oralização. O jogo de adivinhações proposto neste trabalho trabalha o envolvimento e a afetividade dos participantes permitindo extravasar diferentes sentimentos, refletidos na reação dos participantes ao longo das jogadas: alegria, satisfação, raiva, impaciência; além de promover a associação de ideias. Seu design envolveu a participação de diferentes partes interessadas (pesquisadores, professores, estudantes e colaboradores). Para os jogadores, o objetivo é o de "adivinharem" a informação que o outro deseja comunicar utilizando cartões com figuras e fazendo uso de associações.

Nas próximas subseções são detalhados os principais aspectos do protótipo do sistema.

\subsection{O ambiente tecnológico}

O ambiente tecnológico é composto por cartões RFID (radio frequency identification) de $13.56 \mathrm{MHz}$, um leitor RFID compatível, um computador, uma saída de som e um projetor, conforme ilustra a Figura 1.

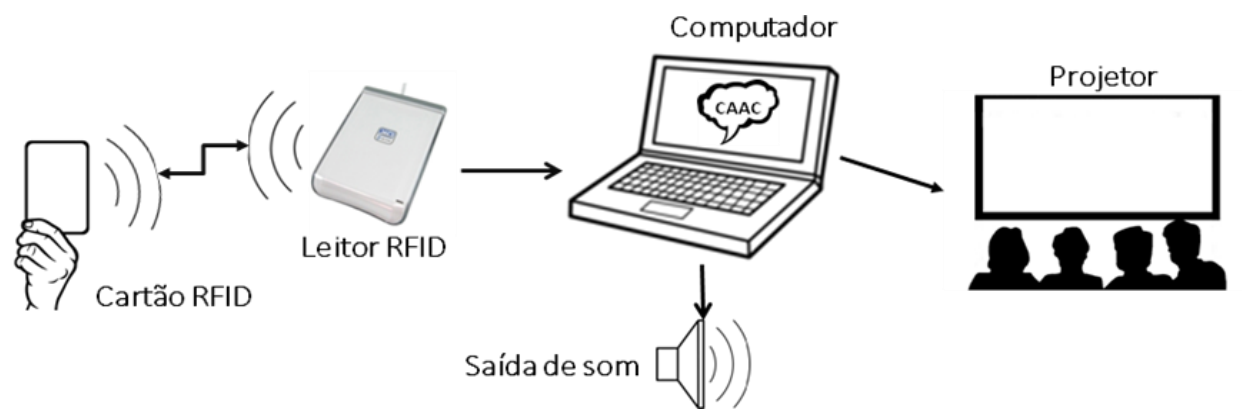

Figura 1 - Visão geral do sistema 
V Congresso Brasileiro de Informática na Educação (CBIE 2016)

Anais do XXVII Simpósio Brasileiro de Informática na Educação (SBIE 2016)

O sistema é manipulado por meio de uma interface tangível, representada pelos cartões RFID. O leitor de RFID é o responsável por ler os códigos dos cartões RFID e enviá-los ao computador que, por sua vez, fica totalmente camuflado pelo uso dos cartões, cujas funcionalidades aparecem no projetor quando são lidos. Cada cartão tem uma vocalização associada a ele, que é ativada quando o cartão é lido.

O software foi desenvolvido utilizando HTML (HyperText Markup Language) e Javascript, de modo que pudesse ser facilmente executado por meio de qualquer navegador, sem a necessidade de instalação. Outra característica do software é que ele não utiliza um banco de dados: todas as figuras e sons estão armazenados em subdiretórios e são acessados por meio do código numérico de cada cartão RFID. Uma vez que cada cartão pode ter associado a ele mais de uma figura e som, a figura ou som que deve ser projetado para os usuários dependem da funcionalidade ativada pelo cartão ou conjunto de cartões. Todos os arquivos de áudio possuem o formato MPEG-4, com extensão m4a e os arquivos de imagens estão em formato JPEG, com extensão jpg.

Os cartões RFID servem tanto para manipular o software quanto para possibilitar a comunicação entre os participantes. Assim, há um conjunto de cartões com as seguintes funcionalidades: a) Eventos do sistema: têm a finalidade de controlar eventos, tais como ativar ou desativar som, fornecer ajuda e informações; b) Eventos do jogo: têm a finalidade de controlar ações durante o jogo, tais como configurar número de equipes, contabilizar ou retirar ponto de determinada equipe, configurar cronômetro, revelar segredo etc.; c) Cartões secretos: cartões com as informações que se deseja comunicar; d) cartões de comunicação: cartões que utilizam pictografia, com palavras e sons associados, com a finalidade de transmitir uma informação ou ideia.

Existem cerca de 150 cartões de comunicação, cujos símbolos utilizados foram selecionados de acordo com as características das mensagens que se gostaria de comunicar em cada partida do jogo (por exemplo, em algumas partidas o objetivo é desvendar "nomes de animações" e, em outras partidas, a meta é descobrir "situações do cotidiano"). As figuras utilizadas nos cartões de comunicação são do mesmo tipo utilizado na comunicação alternativa e aumentativa com pessoas com deficiência de comunicação e foram obtidas no Portal Arasaac ${ }^{1}$.
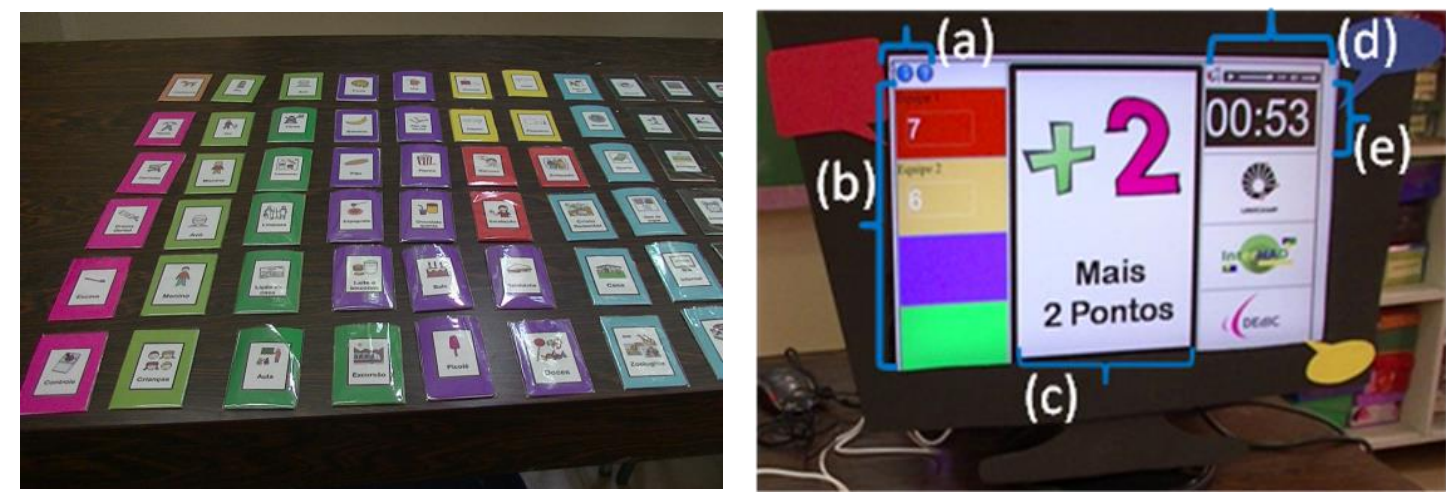

Figura 2 - À esquerda exemplos de cartões de comunicação; à direita, área de projeção durante o jogo

\footnotetext{
${ }^{1}$ Portal Aragonês de Comunicação Alternativa e Ampliada. Disponível em <arasaac.org>.
} 
Para facilitar a identificação das classes dos cartões de comunicação, suas bordas são diferenciadas por cor; por exemplo: cartões que representam pessoas têm a borda verde-claro, cartões que representam comidas têm a borda roxa, cartões que representam objetos têm borda rosa, e assim por diante (Figura 2, à esquerda).

A área de projeção está dividida em cinco subáreas (Figura 2, à direita): a) ajuda e informações; b) pontuação das equipes; c) imagem relativa ao cartão lido (por exemplo, na Figura 2, à direita - item c, o cartão lido é o que pontua uma equipe com dois pontos); d) configurações do sistema; e) cronômetro.

\subsection{Dinâmica do jogo}

O jogo pode ser disputado por até quatro equipes, presencialmente reunidas. A quantidade de equipes deve ser configurada antes do início da disputa por meio dos cartões de eventos do jogo.

O jogo consiste em um membro da equipe (denominado "comunicador") sortear um "cartão secreto" que contém o "nome de uma animação" ou uma "situação do cotidiano", dependendo da partida. Por meio do uso dos cartões de comunicação, o comunicador deve escolher figuras para que o restante da sua equipe possa descobrir a mensagem do cartão secreto. Como exemplo, o comunicador poderia sortear a animação "Bob Esponja" e então escolher cartões de comunicação com as figuras representativas da cor amarela, de uma esponja de lavar louça e do oceano: neste caso uma associação deveria ser feita pelos demais participantes da equipe, uma vez que "Bob Esponja" é uma esponja do mar na cor amarela.

Todos os cartões de comunicação devem ser aproximados do leitor RFID para que a figura e o som associados a cada cartão possam ser projetados/emitidos. É importante ressaltar que o comunicador deve utilizar somente os cartões de comunicação para fazer com que a equipe desvende o segredo, não podendo fazer uso da fala em momento algum. O restante da equipe, que deve tentar descobrir o segredo, pode utilizar a fala normalmente. A equipe tem um tempo pré-determinado para acertar o segredo. Este tempo, é por padrão, estabelecido em dois minutos, mas também é configurável por meio dos cartões de eventos do jogo. Caso a equipe acerte o segredo, deve-se pontuar a equipe, por meio dos cartões de eventos do jogo. Vence o jogo a equipe que possuir o maior número de pontos ao final da partida.

\section{Estudo Exploratório do Cenário Criado}

Este trabalho teve a sua prática realizada por meio de Oficinas $^{2}$ que foram conduzidas junto à Divisão de Educação Infantil e Complementar DEdIC da UNICAMP, mais especificamente na unidade Prodecad ${ }^{3}$, que oferece a educação complementar a crianças de 6 a 14 anos, em horário de contraturno ao ensino regular. Apesar de não haver participantes com deficiência nestas oficinas, a ideia era buscar entender o problema da utilização de interfaces tangíveis na comunicação, antes de experimentá-la em um ambiente que inclua crianças com deficiência.

\footnotetext{
${ }^{2}$ Projeto aprovado pelo Comitê de Ética em Pesquisa da Unicamp, sob número 32213314.8.0000.5404.

${ }^{3} \mathrm{http}: / /$ www.dgrh.unicamp.br/dedic/prodecad
} 
V Congresso Brasileiro de Informática na Educação (CBIE 2016)

Anais do XXVII Simpósio Brasileiro de Informática na Educação (SBIE 2016)

Durante cada Oficina, primeiramente foi apresentado aos participantes o conjunto de artefatos tecnológicos que seriam utilizados na atividade prática, conforme esquematizado nas Figura 1 e 2. Em seguida, foram explicadas para os participantes as regras do jogo e como eles utilizariam cada categoria de cartão. Foi realizada uma demonstração de sorteio de um cartão secreto e de como utilizar os cartões de comunicação para transmitir a informação, bem como o fato de algumas vezes haver a necessidade de usar associação de ideias para descobrir a informação a partir da figura apresentada, pois o conjunto de figuras, apesar de extenso, é finito.
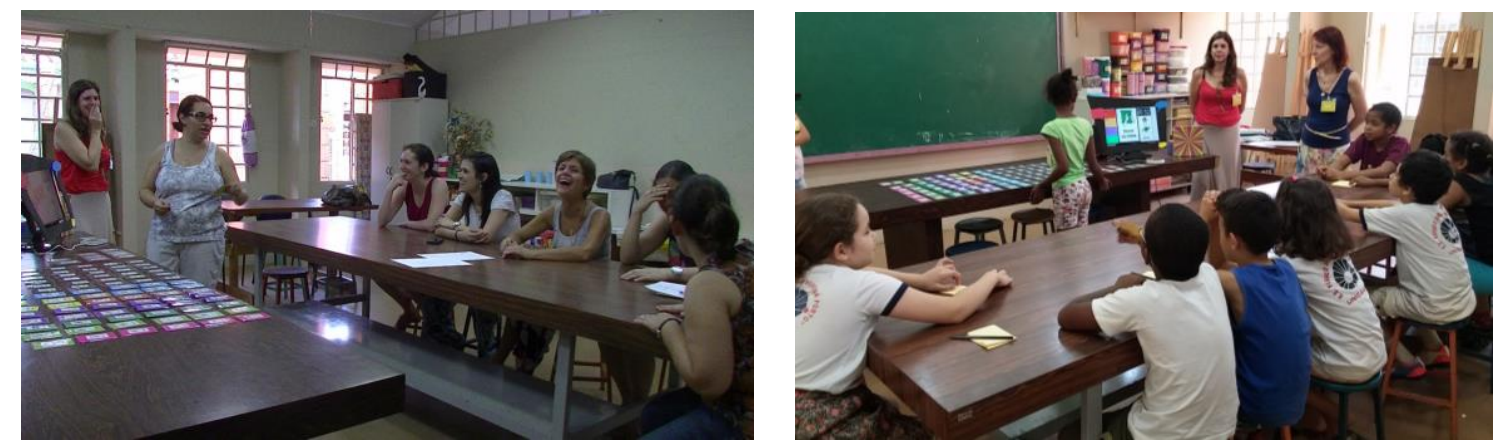

Figura 3 - Professoras e crianças participando de uma das Oficinas

Foram realizadas ao todo cinco oficinas com participantes voluntários, três realizadas com crianças e duas com professores (Figura 3). As crianças que participaram das oficinas tinham de oito a dez anos e os professores de 27 a 54 anos. Todos os jogadores participaram tanto tentando descobrir o segredo quanto como comunicadores em todas as Oficinas. A Oficina 1 teve "Animações" como tema para os cartões secretos e as Oficinas 2 e 3 tiveram como tema "Situações do Cotidiano". As duas oficinas com os professores aconteceram da seguinte maneira: na primeira elas utilizaram o sistema apenas como jogadores; na segunda um professor controlou o jogo, sendo auxiliado pelos pesquisadores quando necessário, e os demais participaram como jogadores. Todas as Oficinas tiveram a participação de dois a três pesquisadores e foram registradas por fotos e por vídeos, que foram utilizados na análise reportada e em observações contidas na seção de discussão.

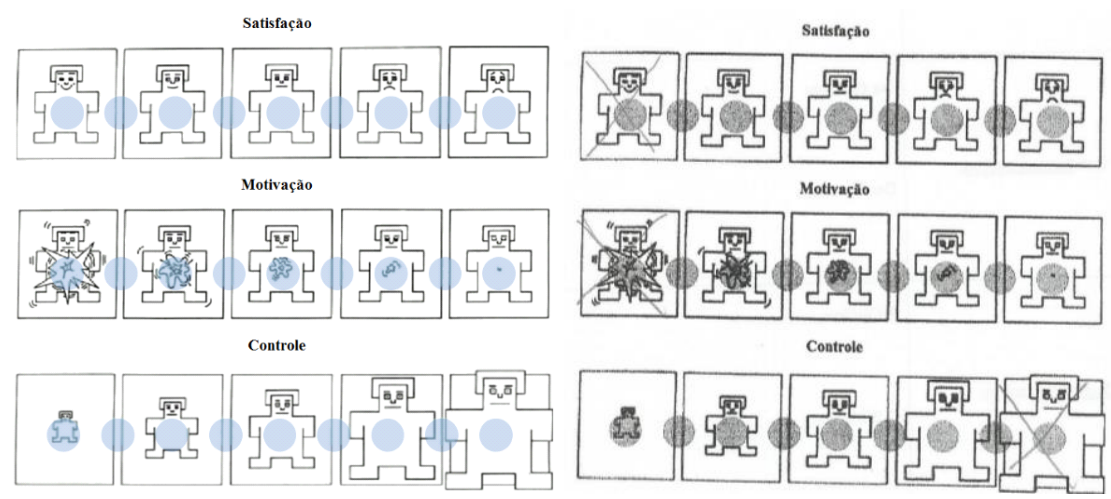

Figura 4: À esquerda, o SAM - Self-Assessment Manikin [Bradley e Lang 1994]; à direita, exemplo do SAM preenchido por um dos participantes

Ao final de cada Oficina, foi realizada uma avaliação, onde os usuários registravam seus estados afetivos relativos à atividade e emitiam opiniões e sugestões 
V Congresso Brasileiro de Informática na Educação (CBIE 2016)

Anais do XXVII Simpósio Brasileiro de Informática na Educação (SBIE 2016)

que eram analisadas para realimentação do sistema. Para a avaliação do estado afetivo, foi utilizado o SAM (Self-Assessment Manikin) [Bradley e Lang 1994], uma forma de avaliação pictórica, que registra diretamente a satisfação, a motivação e o controle do usuário em relação ao sistema (Figura 4). No SAM, cada usuário deveria escolher o nível de satisfação, motivação e controle sobre o sistema em uma escala de 1 a 9 , onde nove significa muito motivado, muito satisfeito ou com muito controle sobre o sistema e um significa pouco motivado, pouco satisfeito ou com pouco controle sobre o sistema.

\section{Resultados e Discussão}

A seguir, analisamos alguns dados que ajudam a responder "se e como tecnologias contemporâneas tangíveis podem ser exploradas em beneficio da comunicação e interação social de forma criativa, lúdica e acessível para a maior extensão possível de usuários".

O termo "Satisfação" refere-se, neste trabalho, à primeira linha do SAM. Em relação à Satisfação, na Figura 5, pode-se observar que a maioria das crianças e professoras respondeu que estavam muito satisfeitos com a Oficina. Nas respostas abertas das avaliações das crianças, os termos "informática" e "interface" aparecem várias vezes como o que mais gostaram na Oficina.
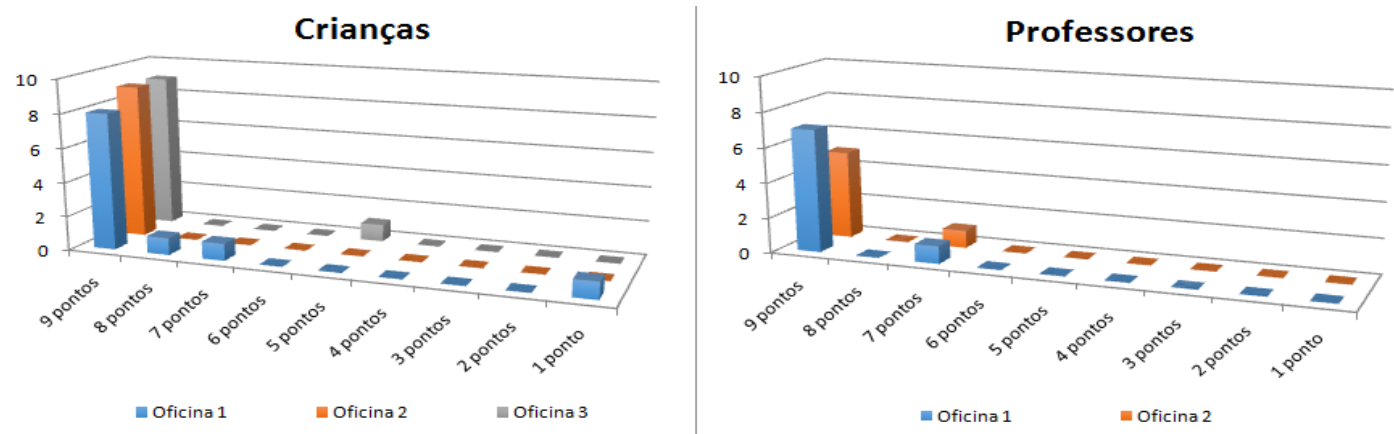

Figura 5 - Avaliação da Satisfação

Neste trabalho, a resposta à motivação refere-se à segunda linha do SAM. Podese observar durante a Oficina que, apesar da pontuação influenciar o jogo, o objetivo da equipe era de acertar sempre, pois os participantes ficavam desapontados quando não acertavam o segredo em tempo. Por meio dos gráficos da Figura 6, percebe-se que a maioria dos participantes estava bastante motivada. Uma criança respondeu que não estava motivada; quando esta criança fez o papel de comunicador não havia conseguido encontrar cartões que pudessem transmitir a mensagem para seus parceiros. Nota-se nesse comportamento a busca por "tradução direta" da mensagem do cartão secreto, enquanto que o jogo pretendia promover a flexibilidade e a associação de ideias para buscar formas diferentes de comunicar alguma coisa. Observou-se que, naturalmente, as crianças tendiam a avaliar melhor a Oficina quando ganhavam a partida.

O controle refere-se ao domínio do participante em relação à utilização do sistema. Pela Figura 7, observa-se que a maioria dos participantes não teve problemas em manipular o sistema. Podemos observar também que na primeira Oficina das crianças, alguns participantes avaliaram o item controle com uma nota inferior à máxima, porém, nas Oficinas seguintes este fato tendeu a desaparecer. $\mathrm{Na} 2^{\mathrm{a}}$ Oficina dos 
V Congresso Brasileiro de Informática na Educação (CBIE 2016)

Anais do XXVII Simpósio Brasileiro de Informática na Educação (SBIE 2016)

professores, onde eles além de participarem como jogadores também gerenciaram o sistema, o item Controle teve uma avaliação com nota mínima. A pessoa que avaliou o controle com essa nota deixou uma observação de que as figuras nos cartões eram muito pequenas, o que dificultava a escolha. Como dito anteriormente, para a projeção utilizase a vocalização da palavra referente à figura do cartão, porém, para a escolha das figuras, seria importante fornecer alternativas para quando o participante possui deficiência visual. Além disso, o número grande de cartões dificulta a localização de determinada figura, quando a busca é linear. As figuras estavam agrupadas por categoria, porém algumas crianças talvez ainda não estivessem familiarizadas com a classificação das palavras, sendo então necessária a criação de alguma estratégia para busca pelas figuras de forma otimizada. $\mathrm{O}$ número de cartões foi reduzido na Oficina $2 \mathrm{e}$ este fato foi apontado como bom por diminuir a quantidade de cartões a serem consultados. Porém, diminuía-se o vocabulário para se expressar determinadas informações, o que em contrapartida, exigia mais o uso de associação de ideias.
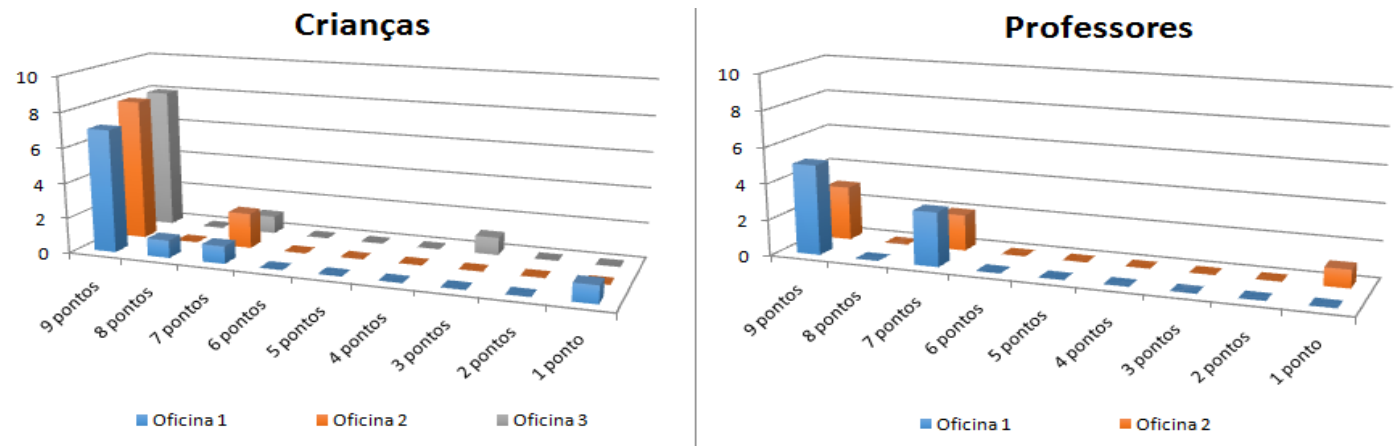

Figura 6 - Avaliação da Motivação

Os pesquisadores observaram também que algumas crianças, que ainda tinham dificuldade na leitura e interpretação, precisavam da ajuda de uma professora para a escolha dos cartões, apesar de cada um deles apresentar um elemento gráfico (utilizado na CAA) correspondente à palavra. Este fato pode ser explicado pela tentativa da criança de buscar um cartão com a "tradução direta" da mensagem que queria transmitir, onde se exigia habilidade de associações de ideias; também sugere a necessidade de investigação sobre os próprios elementos pictográficos utilizados.
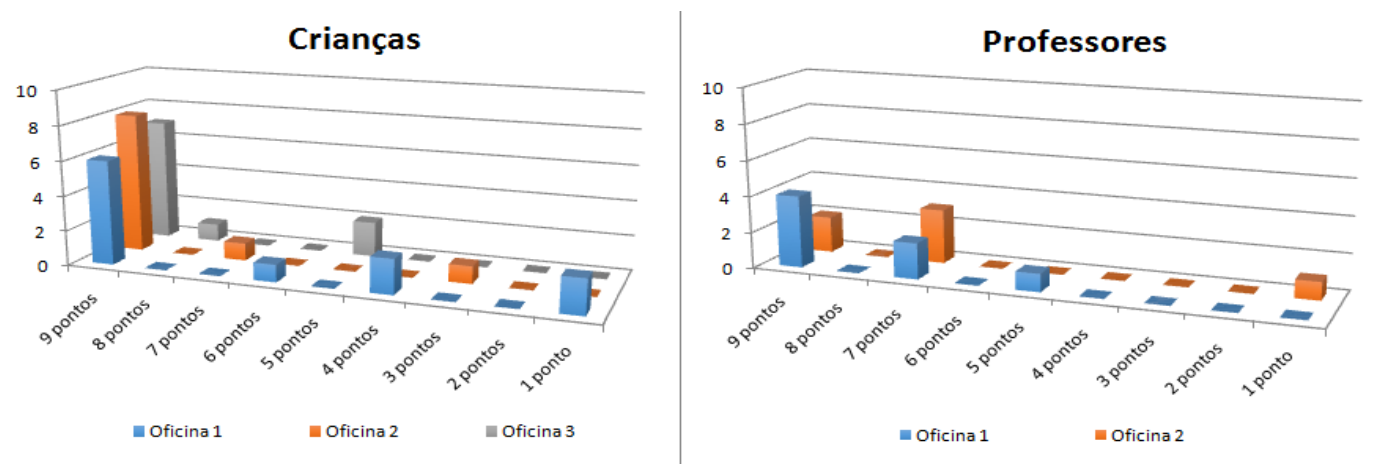

Figura 7- Avaliação do Controle sobre o sistema

Observando os participantes podemos perceber que eles começaram a fazer uso da associação de ideias para transmitir uma informação: por exemplo, uma criança selecionou uma maçã para se referir à cor vermelha; outra selecionou uma bruxa para se 
referir ao adjetivo malvado. Este fato ficou mais visível com o decorrer das Oficinas, quando os participantes que necessitavam descobrir a informação passaram a fazer muito mais sugestões baseados em associação: por exemplo, uma criança sugeriu corretamente a animação "Chapeuzinho Vermelho" quando o comunicador havia mostrado a figura de uma menina e de uma maçã.

Nas oficinas que constam deste estudo piloto não havia criança com deficiência. Para esse cenário, o ambiente criado ainda não contava com elementos de acessibilidade capazes de alcançar uma maior diversidade de pessoas. Apesar de todos os cartões de comunicação conterem saída em áudio, as respostas dos participantes ao jogo eram feitas apenas por via da fala, limitando, por exemplo, a participação de pessoas com deficiência na fala na resposta à adivinhação do segredo. Tornar o sistema acessível é nossa meta de continuidade do trabalho e envolve uma série de etapas, tais como: inclusão de braile nos cartões; colocação das categorias de cartões de comunicação sobre bases texturizadas, de modo que pessoas com deficiência visual possam distinguir categorias; proporcionar a utilização de sons para os cartões de modo que pessoas com deficiência visual possam saber qual é determinado cartão antes que ele seja mostrado às demais pessoas, entre outras. Ainda, a versão acessível será experimentada em escola inclusiva, com a participação de professoras do Apoio Educacional Especializado.

\section{Conclusão}

A CAA tem sido utilizada como ferramenta para proporcionar a comunicação, principalmente entre pessoas com deficiência. Este trabalho investigou a temática da CAA experimentando tecnologia tangível, de maneira a promover habilidades de comunicação via associação de ideias e interação social. $\mathrm{O}$ estudo envolveu o desenho de um ambiente de forma participativa, sua experimentação e observação de uso em contexto educativo. As Oficinas realizadas tiveram como finalidade possibilitar a construção e avaliação incrementais do ambiente tecnológico, como subsídio para o trabalho que inclua crianças com deficiência na fala como próximo passo.

Em nosso sistema, associamos o lúdico com a possibilidade de manipulação de objetos tangíveis, gerando grande interesse e engajamento por parte dos participantes, principalmente das crianças. Este fato pode ser comprovado na avaliação de professores que afirmam "o trabalho com jogos é muito motivador", "oficina é divertida, dinâmica, necessita de atenção, associação". Tanto as crianças quanto os professores conseguiram fazer uso de CAAC para comunicar aos membros da equipe as informações e observouse que os participantes ficavam bastante empolgados quando conseguiam sucesso na comunicação, cumprimentando-se com o "High Five", um gesto que ocorre quando duas pessoas tocam suas mãos no alto simbolizando parceria, amizade e vitória. Durante $\mathrm{o}$ decorrer das Oficinas, percebemos que os participantes aumentaram o número de alternativas para referenciar uma determinada informação, pois deixaram de buscar somente a figura representativa "direta" e passaram a fazer uso de associações.

Finalmente, os resultados sugerem que o design de ambientes que proporcionam a CAAC, baseados em tecnologias contemporâneas, ainda pode ser bastante explorado, especialmente no contexto de ambiente escolar inclusivo (envolvendo crianças com e sem deficiência), nosso próximo passo nesta pesquisa. Em trabalhos futuros esperamos, ainda, ampliar o uso de formas de interação que potencializem a CAAC. 
V Congresso Brasileiro de Informática na Educação (CBIE 2016)

Anais do XXVII Simpósio Brasileiro de Informática na Educação (SBIE 2016)

\section{Agradecimentos}

Apoiaram este trabalho: CNPq (\#308618/2014-9), Instituto de Computação e Grupo Gestor de Benefícios Sociais da Unicamp e Instituto Federal de São Paulo.

\section{Referências}

ASHA - American Speech-Language-Hearing Association. (2016) Disponível em $<$ www.asha.org > . Acesso em 04 fev 2016.

Bradley, M. M. e Lang, P. J. (1994) "Measuring emotion: the self-assessment manikin and the semantic differential". In: Journal of behavior therapy and experimental psychiatry, p. 49-59.

Brasil. (2009) Decreto No 6.949. Promulga a Convenção Internacional sobre os Direitos das Pessoas com Deficiência e seu Protocolo Facultativo. Brasília, 25 ago 2009.

CEUD - Centre for Excellence in Universal Design. (2016) Disponível em $<$ http://universaldesign.ie/What-is-Universal-Design/>. Acesso em 04 fev 2016.

Deus, L. C. J., Motta, C. L. R., Oliveira, C. E. T., Marques, C. V. M. e Chaillou, D. (2011) "Promovendo aprendizagem socializada através de um modelo de plataforma conectivista". In: Simpósio Brasileiro de Informática na Educação. XXII. Aracaju, Brasil.

Garzotto, F. e Bordogna, M. (2010) "Paper-based Multimedia Interaction as Learning Tool for Disabled Children". In: International Conference on Interaction Design and Children. Barcelona, Espanha.

Hayes, G. R., Hirano, S., Marcu, G., Monibi, M., Nguyen, D. H. e Yeganyan, M. (2010) "Interactive visual supports for children with autism". In: Personal and Ubiquitous Computing, 14:663-680.

Hengeveld, B., Hummels, C., Balkom, H., Voort, R., Moor, J. (2013) "Wrapping Up LinguaBytes, For Now". In: International Conference on Tangible, Embedded, and Embodied Interaction. Barcelona, Espanha.

Kishimoto, T. M. (1994) Jogo, Brinquedo, Brincadeira e a Educação. 6. ed. São Paulo: Cortez.

Leo G. e Leroy, G. (2008) "Smartphones to Facilitate Communication and Improve Social Skills of Children with Severe Autism Spectrum Disorder: Special Education Teachers as Proxies". In: International Conference on Interaction Design and Children. Chicago, EUA.

Parton, B. S., Hancock, R., duBusdeValempré, A. D. (2010) “Tangible Manipulatives and Digital Content: The Transparent Link that Benefits Young Deaf Children". In: International Conference on Interaction Design and Children. Barcelona, Espanha.

Ponte, M. (2009) Comunicação Aumentativa: Mitos e Preconceitos. Disponível em $<$ http://www.fappc.pt/>.

Ullmer, B. e Ishii, H. (2000) "Emerging Frameworks for Tangible User Interfaces". In: IBM Systems Journal, 39: 915-31. 